\title{
Risk factors for increased rates of sole ulcers, white line disease, and digital dermatitis in dairy cattle from twenty-seven farms in England and Wales
}

\author{
Z. E. Barker, ${ }^{* 1,2}$ J. R. Amory, ${ }^{* 3}$ J. L. Wright, ${ }^{*}$ S. A. Mason, ${ }^{*}$ R. W. Blowey, $†$ and L. E. Green* \\ *Department of Biological Sciences, University of Warwick, Coventry, CV4 7AL, United Kingdom \\ †Wood Veterinary Group, Gloucester, GL2 4NB, United Kingdom
}

\begin{abstract}
Claw lesion treatment records were recorded by farmers on 27 dairy farms (3,074 cows, 36,432 records) in England and Wales between February 2003 and February 2004. These were combined with farm environment and management data collected using a combination of direct observations, interviews with farmers, and milk recording data. Multilevel models were constructed for the 3 most frequently reported lesions related to lameness, namely, sole ulcers, white line disease, and digital dermatitis. Risks associated with an increased incidence of sole ulcers were parity 4 or greater, the use of roads or concrete cow tracks between the parlor and grazing, the use of lime on free stalls, and housing in free stalls with sparse bedding for 4 mo or more. The risks for white line disease were increasing parity and increasing herd size, cows at pasture by day and housed at night, and solid grooved concrete floors in yards or alleys. Solid grooved flooring was also associated with an increased risk of digital dermatitis, and cows 6 or more months after calving had a decreased risk of a first case of digital dermatitis. These results improve our understanding of the specific risks for 3 important lesions associated with bovine lameness and could be used as interventions in future clinical studies targeted at the reduction of specific lesions.
\end{abstract}

Key words: sole ulcer, white line disease, digital dermatitis, multilevel model

\section{INTRODUCTION}

Sole ulcers, white line disease, and digital dermatitis are 3 of the most frequently reported lesions related to lameness in the United Kingdom (Clarkson et al., 1996; Green et al., 2002). These lesions are painful and, in

\footnotetext{
Received July 29, 2008.

Accepted December 23, 2008.

${ }^{1}$ Corresponding author: zoe.barker@bristol.ac.uk

${ }^{2}$ Present address: Division of Farm Animal Science, Department of Clinical Veterinary Science, University of Bristol, Langford, BS40 5DU, UK.

${ }^{3}$ Present address: Writtle College, Essex, CM1 3RR, UK.
}

the case of sole ulcers and white line disease, cows have lowered nociceptive thresholds for more than $28 \mathrm{~d}$ after treatment (Whay et al., 1998). Milk losses associated with sole ulcers and white line disease were estimated to be, respectively, 574 and $369 \mathrm{~kg} /$ cow per 305 -d lactation in 30 herds (Amory et al., 2008); furthermore, in cattle treated for digital dermatitis, milk yields increased in the months after treatment compared with the months before treatment (Amory et al., 2008). Sole ulcers and white line fissures also have been associated with impaired fertility, and sole ulcers have been associated with an increased occurrence of milk fever (Sogstad et al., 2006). In addition to impaired welfare and increased disease, lameness causes economic loss for farmers (Kossaibati and Esslemont, 1997).

Few researchers have reported risk factors associated with an increase in specific lesions compared with risks for poor locomotion as a whole. It is likely that the lack of such studies is largely due to the difficulties associated with collecting and collating accurate data on individual cows. Among the studies published for specific lesions, Singh et al. (1993b) reported an increased incidence of sole ulcers associated with increased standing times, and Faye and Lescourret (1989) reported that feeding corn silage increased the risk of sole ulcers. Sogstad et al. (2005) reported that cows 5 to 7 mo after calving and cows in their first parity had an increased risk of sole hemorrhage in a study of 1,547 cows on 57 farms with short free stalls. In the same study, solid concrete alley floors and stage of lactation between 3 and 5 mo were associated with an increased risk of white line hemorrhage. Sogstad et al. (2005) also reported an association between slatted concrete alley floors and an increased risk of white line fissures. This is likely due to the uneven distribution of force within the claw capsule when the claw is only partially supported (Hinterhofer et al., 2006). Somers et al. (2005) reported an increase in the incidence of digital dermatitis associated with restricted or zero grazing, and a decrease risk of digital dermatitis when cows were housed in buildings with slatted floors cleaned with scrapers compared with solid floors. Finally, Wells et al. (1999) reported that hiring a commercial claw trimmer and 


\begin{tabular}{|c|c|c|c|c|c|c|c|c|c|c|}
\hline $\begin{array}{c}\text { Cow } \\
\text { number/ } \\
\text { identity }\end{array}$ & $\begin{array}{c}\text { Site of } \\
\text { lesion } \\
\text { (place a } \\
\text { cross) }\end{array}$ & $\begin{array}{l}\text { Foot affected } \\
\text { (circle one } \\
\text { only) }\end{array}$ & $\begin{array}{c}\text { Lame } \\
\text { (circle one) }\end{array}$ & $\begin{array}{c}\text { Lesions seen } \\
\text { (circle all appropriate, } \\
\text { star * cause) }\end{array}$ & $\begin{array}{l}\text { Date today } \\
\text { (dd/mm/yy) }\end{array}$ & $\begin{array}{c}\text { Calving } \\
\text { Date } \\
(\mathrm{dd} / \mathrm{mm} / \mathrm{yy})\end{array}$ & $\begin{array}{c}\text { Lactation } \\
\text { No. }\end{array}$ & $\begin{array}{l}\text { Who trimmed foot } \\
\text { (circle all } \\
\text { appropriate) }\end{array}$ & $\begin{array}{c}\text { Treatment given } \\
\text { (if antibiotics } \\
\text { given please state } \\
\text { dose) }\end{array}$ & $\begin{array}{c}\text { No of Repeat } \\
\text { Treatments }\end{array}$ \\
\hline & & $\begin{array}{ll}\text { LF } & \text { RF } \\
\text { LH } & \text { RH }\end{array}$ & $\begin{array}{c}\text { Sound } \\
\text { Not sound } \\
\text { Definitely } \\
\text { lame } \\
\text { Hobbling }\end{array}$ & $\begin{array}{l}\text { Sole ulcer White line } \\
\text { Digital dermatitis Foul } \\
\text { Other (please state) }\end{array}$ & & & & $\begin{array}{c}\text { Farmer } \\
\text { Foot Trimmer } \\
\text { Vet }\end{array}$ & $\begin{array}{c}\text { e.g. trim, excenol, } \\
\text { block }\end{array}$ & \\
\hline
\end{tabular}

Figure 1. Form for recording claw lesions observed during the treatment of lame cows.

failing to wash claw-trimming equipment between cows were associated with an increased incidence of digital dermatitis. In this paper, we consider the risks associated with the 3 most common lesions associated with lameness in a cohort study of 27 farms.

\section{MATERIALS AND METHODS}

\section{Data Collection}

Participating farmers were convenience selected from a database of farmers who had previously participated in a study of mastitis (Peeler et al., 2003). Parity, cow, and farm management data were collected for cattle on 29 dairy farms in England and Wales. Calving date, parity number, monthly milk yield, and breed data were sourced from National Milk Records. Participating farmers were asked to record claw lesions observed during their normal treatment of lame cows. Claw lesions observed at treatments between February 2003 and February 2004 were recorded on a standardized recording form (Figure 1). Farmers were requested to indicate the type of lesion treated and the location of the lesion on the claw. If the type and location of the lesion did not correspond, then the lesion type was recorded as unknown to reduce misdiagnosis. Where more than 1 lesion was present on the claw, farmers were requested to indicate the lesion they believed was most likely to be causing the lameness observed in that cow. All farmers were invited to 1 of 5 evening meetings that included training on lesion recognition. At these meetings, attending farmers were provided with and trained to use a laminated color reference sheet, which gave pictorial examples and written descriptions of 17 common foot lesions, to aid lesion identification. Farmers who did not attend an evening meeting were provided with a laminated color reference sheet and trained to use the pictures and lesion definitions to identify the lesions they were recording.

During the same period, the farms were visited 4 times by 1 researcher (Z. B.) and 1 of 3 colleagues. At each visit, the researchers collected all outstand- ing lesion records from the farmer. In addition, at each visit the locomotion of every cow was also assessed using a 3 -point scale, where 1 was normal and 3 was definitely lame (Barker et al., 2007). The hocks of each cow were assessed for swelling, hair loss, or abrasion. A 3 -point scale was used, where $1=$ no swelling, hair loss, or abscesses, $2=$ mild swelling and hair loss, but no abscesses, and $3=$ severe (immediately obvious) swelling, abscesses, or both. Direct observations of the farm environment, in both summer and winter, were made by the researchers visiting the farm in both the summer grazing period and winter housing period. Information regarding the management of the dairy herd during the previous 12 mo was collected using a farmer interview (Barker et al., 2007). The data included general farm information, nutritional management, cattle breed and replacement management, heifer and dry cow management, and lameness treatment and control.

On all the farms enrolled, cows were turned out to pasture during the summer grazing period, with the exception of 1 farm where the high-yielding cows were housed all year round but the low yield cows were allowed to graze during the summer. All farmers fed their cattle a conserved forage ration with a compound feed or blend during the winter housing period. The dairy rations were presented as a TMR or as forage with additional concentrate fed in or out of parlor.

\section{Data Handling}

A data set was generated with farm identification, cow identification, parity, month from calving (MC), and monthly milk yield. Housing dates were used to define where each cow was kept at night and during the day for each month of the lactation (cow-month). For each cow-month, the following were defined: milking status (in milk or dry), housing status (housed $24 \mathrm{~h}$ a day, pasture $24 \mathrm{~h}$ a day, pasture by day and housed by night), lying surface [deep bedding (straw or sand), sparse bedding (sawdust, straw, or sand), and pasture], outdoor walking surface (no tracks, rough tracks, concrete or tarmac tracks), indoor walking surface (non- 
grooved solid concrete, grooved solid concrete, slatted concrete) and treatments for sole ulcers, white line disease, and digital dermatitis. The outcome of interest was the first lesion of a type per claw in a given parity. Accurate drying off dates were not available, so for the purposes of these analyses, it was assumed that a cow was dry 2 wk after the date of the 305-d milk recording.

\section{Data Analysis}

One herd of 57 Ayrshire cows (777 records) was excluded because this herd was the only herd with this breed of cattle. One farm with an extremely high reported incidence of digital dermatitis (80 cows, 969 records) was not analyzed further because it was an outlying farm. A further 18 cows (223 records) that were of breeds other than Holstein-Friesian were also excluded from the data set. The models were constructed using 37,401 monthly milk records from 3,154 cows on 28 farms. The presence or absence of sole ulcers, white line disease, or digital dermatitis in a given month was used as a binary outcome variable in 3 multilevel models; the comparison group was cattle with no claw lesion. Each model was a binomial logistic regression model with MC nested within cow and cows nested within farms. Results are presented as odds ratios and confidence intervals $(1.96 \times \mathrm{SE})$.

For each lesion outcome, all explanatory variables were screened. Variables with $P<0.2$ were taken forward for multivariable analysis. Variables were left in the final model after backward elimination when $P<$ 0.05. Parity and MC were included in all models. All nonsignificant variables were reentered into the final models one by one to investigate residual confounding, and any variable significant at $P<0.05$ was included in the model. The Hosmer-Lemeshow goodness-of-fit test was used to assess model fit. All statistical analyses were carried out using MLwiN version 2.01 (Centre for Multilevel Modeling, University of Bristol, UK).

The model took the form

$$
\operatorname{Logit} \mathrm{Y}_{\mathrm{ijk}}=\beta 0+\beta \mathrm{X}_{\mathrm{k}}+\beta \mathrm{X}_{\mathrm{jk}} \beta \mathrm{X}_{\mathrm{ijk}}+\mathrm{v}_{\mathrm{jk}}+\mathrm{u}_{\mathrm{j}}+\mathrm{e}_{\mathrm{ijk}}
$$

where $\mathrm{Y}_{\mathrm{ijk}}$ is the binary outcome of lesion treated in cow-month $\mathrm{i}$, cow $\mathrm{j}$, and farm $\mathrm{k} ; \beta 0$ is the intercept; $\beta$ are coefficients for the vector of $\mathrm{X}$ variables varying at levels $\mathrm{k}, \mathrm{jk}$, and $\mathrm{ijk} ; \mathrm{v}_{\mathrm{jk}}$ is the variance between farms; $\mathrm{u}_{\mathrm{j}}$ is the variance between cows; and $\mathrm{e}_{\mathrm{ijk}}$ is the variance between months.

\section{RESULTS}

\section{Summary Data}

The number of cows with sole ulcers, white line disease, and digital dermatitis lesions associated with potential risk factors tested in these analyses are summarized in Table 1 . The rate of all 3 lesions per 100 cow-months in dry cows was significantly lower than that of milking cows. The rate of digital dermatitis per 100 cow-months for small herds ( $<79$ cows) was very small compared with medium (80 to 159 cows) and large ( $>160$ cows) herds.

\section{Sole Ulcers}

Cows in parity 4 or greater had a greater risk of sole ulcers than first-parity cows (Table 2). Both the absence of cow tracks (i.e., direct access to the field from the farmyard) and the use of concrete cow tracks or roadways were associated with an increased risk of sole ulcers compared with rough dirt or stone tracks. Using lime in the free stalls was associated with an increased risk of sole ulcers. Having cows housed on sparse bedding for at least $4 \mathrm{mo}$, compared with not housed on sparse bedding for this time, was also associated with an increased risk of sole ulcers.

\section{White Line Disease}

The risk of white line disease increased with solid grooved concrete floors in housing and yards, compared with other floor surfaces (Table 2). White line disease was also positively associated with increasing herd size, increasing parity, and being in the $3 \mathrm{MC}$. The risk of white line disease also increased when cows had access to pasture in the day but were housed at night, compared with being housed $24 \mathrm{~h}$ per day.

\section{Digital Dermatitis}

The risk of digital dermatitis increased with solid grooved concrete floors in housing and yards, compared with solid nongrooved concrete floors. Being in the sixth or greater $\mathrm{MC}$ was associated with a reduced risk of digital dermatitis (Table 2).

\section{Multilevel Models}

For each model, the observed and expected lesion outcomes were divided into deciles and compared. There were differences between the observed and expected variables for the sole ulcer model. The model underestimated the number of lesions. There was good agreement between the expected and observed values for the white line disease model. After adjustment for the effect of a single farm with a high incidence of digital dermatitis and an unusual distribution of lesions over time, the agreement between expected and observed values for the digital dermatitis model was good. 
Table 1. Number of sole ulcer, white line disease, and digital dermatitis lesions treated for different cow and farm characteristics ${ }^{1}$

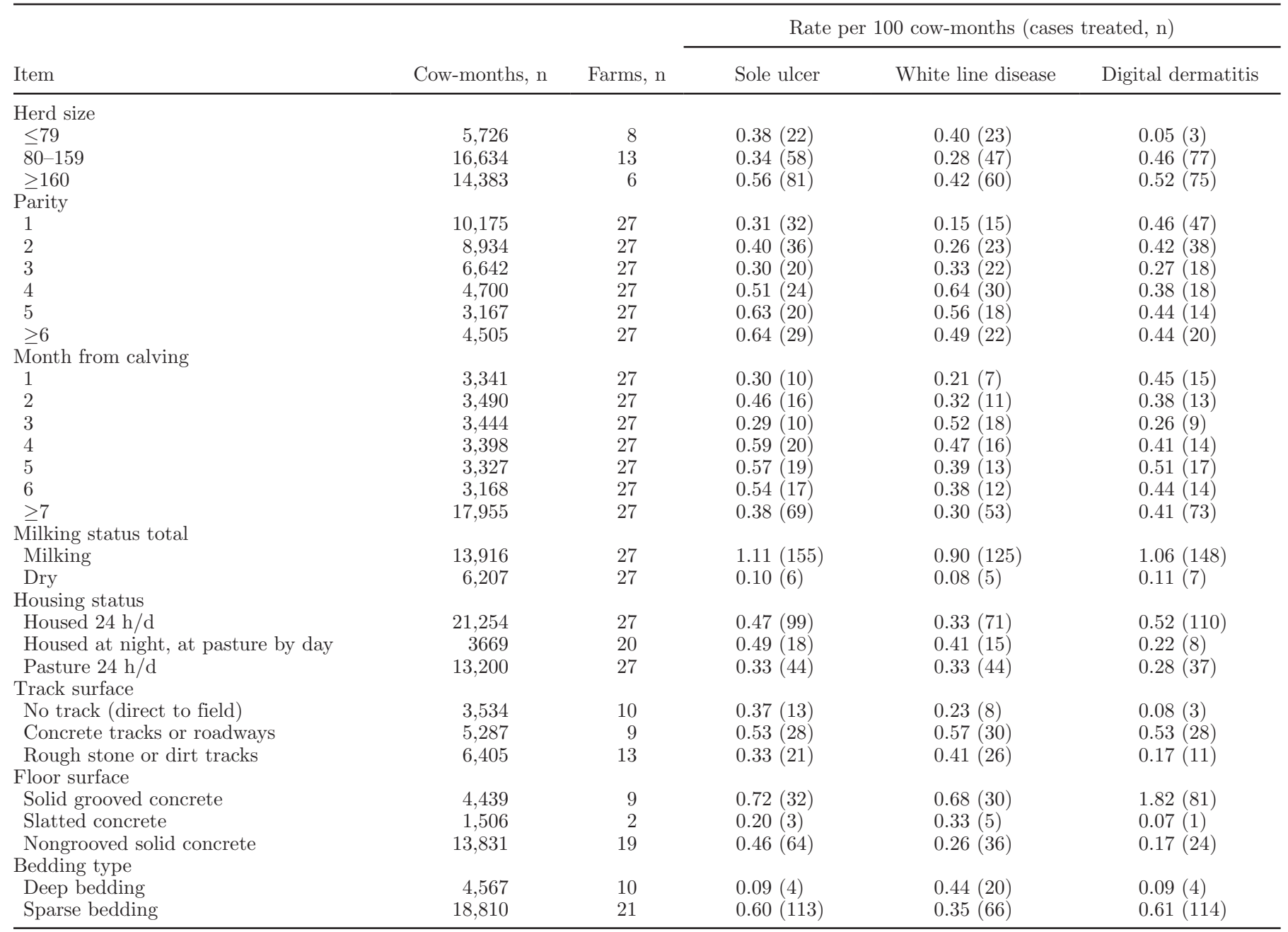

${ }^{1}$ Farms may be represented in more than one subcategory because of the different housing types used for different cow groups (e.g., dry cows) and cow-months.

\section{DISCUSSION}

There was an increased risk of white line disease and sole ulcers with increasing parity and a decreased risk of digital dermatitis with increasing parity in this study. Similar associations with parity have been reported in previous studies by Potzsch et al. (2003), Alban (1995), and Somers et al. (2005), respectively.

Many management risks for lameness were lesion specific. There were marked differences in risk factors between sole ulcers and white line disease. This provides further support for the theory that the etiology of these diseases differ (Le Fevre et al., 2001), although they might still have a similar pathogenesis (Mulling and Lischer, 2002). The risks for each lesion are discussed below.

Sole ulcers were positively associated with sparse bedding in free stalls, walking on hard tracks, absence of any track, and parity. Barker et al. (2007) associated free stalls sparsely bedded with sawdust over mats or mattresses with poor locomotion scores in the same cattle as those in the current study. In the current study, sole ulcer was the lesion associated with this risk of a lying surface with sparse bedding (sawdust, straw, or sand) on concrete, mats, or mattresses, compared with a lying surface of deep bedding (straw or sand) or pasture. Total lack of bedding has also been associated with an increased risk of sole ulcers (Leonard et al., 1994). The data in the current study were longitudinal, and from these we see that the length of time cows were exposed to sparse bedding was important, because the risk of sole ulcers was only significantly increased when cows were housed on sparse bedding for 4 mo or more. One hypothesis for the delayed onset is that there might be a lag between first exposure to sparse bedding and the development of visible lesions at the sole surface, which 
Table 2. Binomial logistic mixed effects models for risk factors for sole ulcer, white line disease, and digital dermatitis lameness

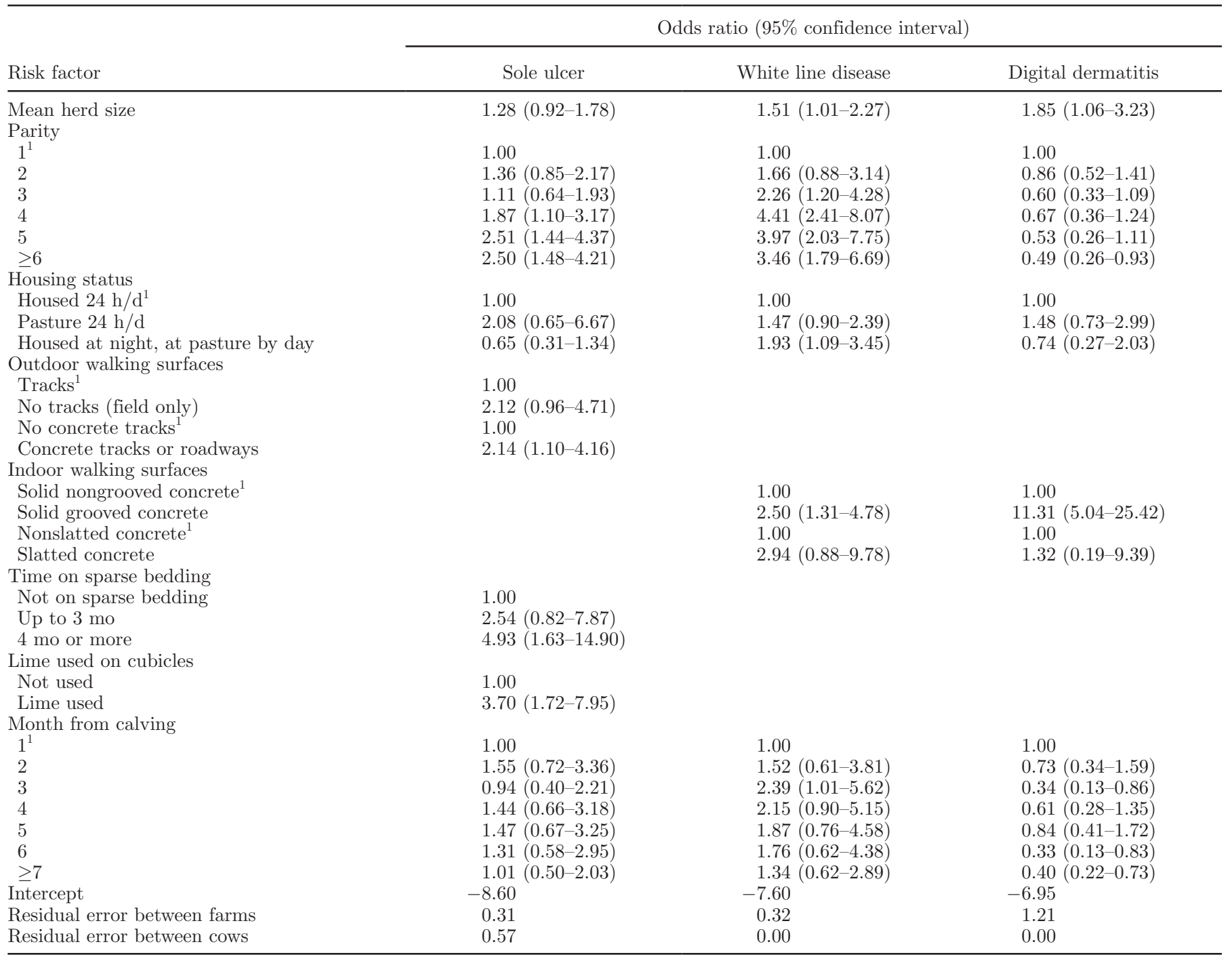

${ }^{1}$ Reference category.

is dependent on the depth of the sole horn and the rate of horn growth. Taking into account the reported horn growth rates in adult cows, as summarized by Vermunt and Greenough (1995), and the typical sole horn depth, as reported by Toussaint Raven (1985), a sole ulcer may take 4 to 6 wk to become visible at the sole surface. A second hypothesis for the delayed onset in the development of sole ulcers was that sole ulcers are secondary to swollen hocks. The number and severity of hock lesions in these same cattle was greatest in late winter (January to February), when cows had been housed for 3 to 4 mo, compared with early winter and summer (Barker, 2007). These swollen hocks might not cause lameness per se but might be painful, and the action of lying down on unyielding lying surfaces may result in cows preferring to stand and so increase their standing time. It seems more likely that sole ulcers are linked to standing for longer than lying on hard surfaces. Tucker et al. (2003) reported that cows prefer deeply bedded free stalls to minimal bedding on top of mattresses, and Singh et al. (1993a) reported that cows lay down for longer on more comfortable bedding surfaces. Singh et al. (1993b) also reported that cows that stood for longer had increased sole lesion scores and lameness (Singh et al., 1993b). The prolonged time to development of hock lesions together with, or overlapping with, the length of time taken for sole ulcers to develop may explain why some cows were at pasture when they were lame with sole ulcers (Table 2).

There was an increased risk of having sole ulcers associated with the use of lime on the free stalls. This relationship may be due in part to the use of lime be- 
ing more common with a certain bedding type when it is being used sparingly on cubicles (e.g., sparse straw and sparse sawdust). It is also possible that lime could damage the horn of the foot or the skin of the hock and increase the abrasion. This would therefore either cause sole ulcers directly or cause sole ulcers indirectly if raw skin on the hocks made cows reluctant to lie down, increased their standing times, and increased the risk of sole ulcers. Unlike in previous studies, no aspects of cubicle design were significant in the current model for sole ulcers.

In the current study, hard tracks and roadways of concrete or tarmac were also associated with an increased risk of sole ulcers. These walking surfaces would have led to flat, thin soles because of the wear of the claw horn that occurs when cows walk or are kept on hard surfaces, compared with soft surfaces such as pasture (Hahn et al., 1986). This excessive wear results in the loss of the natural concavity of the sole (Tranter and Morris, 1992). Both wear and loss of concavity have been reported to increase the risk of sole ulcers (Van Amstel et al., 2004).

There was a trend for an increased risk of sole ulcers when there were no cow tracks (i.e., cows walking straight from the farmyard into fields). This might be a chance finding, but it is possible that it occurred because these farms tended to have a primary gateway from the yard to all the fields that was often rough (the ground is uneven and stones are visible at the surface because of many cattle walking through this narrow space) from frequent use (personal observation). One hypothesis for the association between lack of cow tracks and sole ulcers is that stones from heavily rutted areas may cause physical damage to the sole horn, especially when the stones are carried onto concrete yards. Moisture in the gateways may also soften the claw horn, increasing the chance of damage to the sole because loose stones carried onto the concrete yards may cause pressure points on the sole.

The current study and previous work now provide strong evidence that sole ulcers, and lameness attributable to sole ulcers, are more likely when cows stand for long periods, and that they are more likely to stand for long periods if their lying surface is not comfortable. In addition, there is good evidence that wear of the weight-bearing claw horn thins the sole and increases the contact of the sole with the ground. The higher incidence of sole ulcers associated with increasing time on a hard surface and increasing parity indicate that continued exposure to hard lying and walking surfaces over time (i.e., many months and many lactations) is increasingly detrimental to claw health and may also impair recovery. It seems highly likely that management of cattle to avoid these risks would be highly effective at reducing sole ulcers, the most painful lesion (Whay et al., 1998) with the greatest reduction in milk yield (Amory et al., 2008).

There was an increased risk of white line disease when cows were housed at night and grazing by day, compared with being housed $24 \mathrm{~h}$ per day. There was a suggestion that this risk was present, but less robust, in cows housed at pasture for $24 \mathrm{~h}$ per day - cattle still walk along tracks to the milking parlor if at pasture for $24 \mathrm{~h}$ per day. Herding cattle on tracks increases the risk of twisting foot actions and abnormal foot loading, which is hypothesized to be associated with increasing the risk of white line disease (Chesterton, 2004). There are several possible explanations for the extra risk from partly housed, partly grazed cattle that are not mutually exclusive. Two possibilities are that the claw horn is softened either by wet pasture or by contact with concrete with slurry (or both). This would increase the wear of the sole horn and so increase the risk of white line disease. A further 2 possibilities relate to social behavior in the herd: different social hierarchies may exist at pasture and in housing, so the social stability of a herd would be adversely affected by the daily movement between pasture and house; alternatively, the social hierarchy of a herd might be less stable when cows are housed at night and at pasture by day because cattle might be mixed as they are moved from field to shed each day. Disruption to the social hierarchy might lead to more evasive movements that increase the risk of white line disease (Chesterton, 2004). Finally, spring and autumn activity is also correlated in some herds with spring and autumn calving, when white line disease might be more likely (Tarlton et al., 2002).

White line disease was also associated with increasing herd size in the current study. Herd size was associated with group size, and this also affects the number and type of social interactions and may lead to more avoidance behaviors.

In the current study, the risk of white line disease increased more than 2-fold when cows were exposed to solid grooved concrete floors in alleyways or yards. This is perhaps an unexpected finding, given that diamondor square-shaped shallow grooving of concrete is used to reduce the slipperiness of worn concrete. It should be noted that this is very different from the deep parallel grooves that can be set into concrete when first laid. It appears that shallow grooves are effective initially, but numerous observations (by Z. B.) of both cows and researchers slipping on solid grooved concrete suggest that the increased friction offered by solid grooved concrete was lost over time and that regrooving of concrete needs to be regular to maintain the initial benefits. Slippery floor surfaces have been associated with an increase in lameness (Faull et al., 1996) and alterations in gait 
(Telezhenko and Bergsten, 2005). Faull et al. (1996) hypothesized that altered weight bearing on the claw resulting from the abnormal gait of cows on slippery floors increased pressure on the sole and white line. In addition to an altered gait, some cows stumble or slip, resulting in increased shearing forces and impaction as a cow attempts to regain her balance (personal observations). Further investigation of the gait, slip incidents, and general behavior of individual cows on different floor surfaces in comparison with individual cow lesion records for white line disease would provide stronger evidence for this link. Despite the strong association between sole ulcers and lying comfort and, by inference, lying and standing times, there was no such association with white line disease. This could be an indication that the way in which cows move over various floor surfaces has a greater influence on white line disease than the overall amount of time spent standing.

Disruptions to the growth of horn around the time of calving, which can lead to poor-quality horn formation (Tarlton et al., 2002), may explain the increase in lesions of the white line 3 mo after calving. Separation or penetration of the white line may be more likely where horn is of poor quality (Collis et al., 2004).

In the current study, solid grooved concrete was also associated with an increased risk of digital dermatitis. It is possible that there is an indirect association between digital dermatitis and solid grooved floors. One such factor is the quantity of slurry present on the floors of alleys and yards. A small quantity of slurry remains in these grooves after the floor has been scraped. This might act as a reservoir for bacteria. Wells et al. (1999) reported that the risk of digital dermatitis for cows on solid grooved concrete was 2.7-fold that of cows on textured concrete. In contrast, floor types that reduce the accumulation of slurry have been associated with a decreased risk of digital dermatitis (Somers et al., 2005). No other risks for digital dermatitis were apparent in the current study, except that the risk for the first case reduced after $6 \mathrm{MC}$; this may be because cows were already affected with their first case by 6 mo after calving. It is common that risks for infectious diseases are not primarily management related, but rather host driven, and the study presented here did not capture many host risks.

The models used in the current paper allowed the effects of both individual cow and herd risks to be compared for sole ulcers, white line disease, and digital dermatitis. Although a large number of cattle were included in this analysis, the data came from 27 farms, and this must be remembered when considering the generalizability of farm-level risks, both in their universality (e.g., grooved floors may vary by country) and lack of variability (e.g., it was not possible to evaluate the risk of concrete floors per se because all cattle spent time on concrete). The use of a cow-month level within the model allowed the appropriate lying and underfoot surfaces to be linked temporally with lesions. However, the use of data at a cow-month level means that the occurrence of lesions was a rare event, which may have affected the fit of the models and may explain the differences between observed and expected values reported for the sole ulcer model. It is therefore possible that effects of some of the variables in the sole ulcer model were over- or underestimated, or, more likely, that some important variable or variables were not measured. In spite of this, there is good supporting evidence for an association between the results from the current study and previous studies.

There was a large amount of variation in rate of digital dermatitis among farms, probably because of the infectious nature of this lesion. Treatment and control of digital dermatitis is often carried out at a herd level and the method, frequency, and effectiveness of these control strategies vary by farm. There was greater unexplained variation among cows than among herds in the sole ulcer model (Table 2) and, in contrast, there was no variation among cows in the white line disease and digital dermatitis models, suggesting that maybe sole ulcers were more likely in certain cows, whereas white line disease and digital dermatitis were primarily herd exposure diseases.

It was not possible to quantify the number of lesions that were misclassified by the farmers because it was not feasible for the researchers to be present during the treatment of lame cows. The provision of a color lesion reference sheet with prior instructions on its use and the standardized recording form minimized the number of lesions that were incorrectly identified by the farmer. The present study was part of a larger intervention study, so it was not desirable to influence the type and frequency of treatment for lameness the farmers carried out. Consequently, the farmers were not given training to recognize lame cows. Farmers are known to underestimate the number of lame cows on their farms (Whay, 2002). The number of lesions recorded by the farmers is therefore likely to be an underestimate of the true number of lesions because not all lame cows received treatment. This underestimation of overall lesion numbers would not affect the interpretation of the results because the distribution of lesions within each farm would not be altered unless farmers were biased toward treating cows with certain lesions; this seems improbable because the lesion associated with lameness will not be known until the foot is inspected.

All the 3 common lesions in lame cows were associated with cattle age and housing. However, other risks for the lesions differed. There is now quite strong evi- 
dence that sole ulcers are linked to uncomfortable lying conditions or standing for prolonged periods and that all 3 lesions are associated with aspects of hard floor surfaces. The risks for white line disease and digital dermatitis were less clear than the risks for sole ulcers. To successfully reduce lameness on farms, it is essential that interventions be targeted at the risks factors for the main lesion or lesions causing lameness on each farm. Although the results of this study add to the current knowledge on lesion-specific risks, they also highlight the need for further investigation of risks for white line disease and digital dermatitis.

\section{REFERENCES}

Alban, L. 1995. Lameness in Danish dairy cows: Frequency and possible risk factors. Prev. Vet. Med. 22:213-225.

Amory, J. R., Z. E. Barker, J. L. Wright, S. A. Mason, R. W. Blowey, and L. E. Green. 2008. Associations between sole ulcer, white line disease and digital dermatitis and the milk yield of 1824 dairy cows on 30 dairy cow farms in England and Wales from February 2003-November 2004. Prev. Vet. Med. 83:381-391.

Barker, Z. E. 2007. Epidemiology of lameness in dairy cows. PhD Thesis. Univ. Warwick, Coventry, UK.

Barker, Z. E., J. R. Amory, J. L. Wright, R. W. Blowey, and L. E. Green. 2007. Management factors associated with impaired locomotion in dairy cows in England and Wales. J. Dairy Sci. 90:3270-3277.

Chesterton, N. 2004. Linking farm physical condition, herd management and cow behaviour to the distributions of foot lesions causing lameness in pasture-red dairy cattle in New Zealand. Page 200 in Proc. 13th Int. Symp. 5th Conf. Lameness in Ruminants, Maribor, Slovenia. Ungula, Zemljic and Co., Maribor, Slovenia.

Clarkson, M. J., D. Y. Downham, W. B. Faull, J. W. Hughes, F. J. Manson, J. B. Merritt, R. D. Murray, W. B. Russell, J. E. Sutherst, and W. R. Ward. 1996. Incidence and prevalence of lameness in dairy cattle. Vet. Rec. 138:563-567.

Collis, V. J., L. E. Green, R. W. Blowey, A. J. Packington, and R. H. C. Bonser. 2004. Testing white line strength in the dairy cow. J. Dairy Sci. 87:2874-2880.

Faull, W. B., J. W. Hughes, M. J. Clarkson, D. Y. Downham, F. J. Manson, J. B. Merritt, R. D. Murray, W. B. Russell, J. E. Sutherst, and W. R. Ward. 1996. Epidemiology of lameness in dairy cattle: The influence of cubicles and indoor and outdoor walking surfaces. Vet. Rec. 139:130-136.

Faye, B., and F. Lescourret. 1989. Environmental factors associated with lameness in dairy cattle. Prev. Vet. Med. 7:267-287.

Green, L. E., V. J. Hedges, Y. H. Schukken, R. W. Blowey, and A. J. Packington. 2002. The impact of clinical lameness on the milk yield of dairy cows. J. Dairy Sci. 85:2250-2256.

Hahn, M. V., B. T. McDaniel, and J. C. Wilk. 1986. Rates of hoof growth and wear in Holstein cattle. J. Dairy Sci. 69:2148-2156.

Hinterhofer, C., J. C. Ferguson, V. Apprich, H. Haider, and C. Stanek. 2006. Slatted floors and solid floors: Stress and strain on the bovine hoof capsule analyzed in finite element analysis. J. Dairy Sci. 89:155-162.

Kossaibati, M. A., and R. J. Esslemont. 1997. The costs of production diseases in dairy herds in England. Vet. J. 154:41-51.
Le Fevre, A. M., D. N. Logue, J. E. Offer, I. McKendrick, and G. Gettinby. 2001. Correlations of measurements of subclinical claw horn lesions in dairy cattle. Vet. Rec. 148:135-138.

Leonard, F. C., J. O'Connell, and K. O'Farrell. 1994. Effect of different housing conditions on behavior and foot lesions in Friesian heifers. Vet. Rec. 134:490-494.

Mulling, C. K. W., and C. J. Lischer. 2002. New aspects on etiology and pathogenesis of laminitis in cattle. Pages 236-247 in XXII World Buiatrics Congr., Hanover, Germany. M. Kaske, H. Scholz, and M. Holsterhinken, ed. Klinik fur Rinderkrankheiten, Hannover, Germany.

Peeler, E. J., M. J. Green, J. L. Fitzpatrick, and L. E. Green. 2003. The association between quarter somatic-cell counts and clinical mastitis in three British dairy herds. Prev. Vet. Med. 59:169180.

Potzsch, C. J., V. J. Collis, R. W. Blowey, A. J. Packington, and L. E. Green. 2003. The impact of parity and duration of biotin supplementation on white line disease lameness in dairy cattle. J. Dairy Sci. 86:2577-2582.

Singh, S. S., W. R. Ward, K. Lautenbach, J. W. Hughes, and R. D. Murray. 1993a. Behaviour of first lactation and adult dairy cows while housed and at pasture and its relationship with sole lesions. Vet. Rec. 133:469-474.

Singh, S. S., W. R. Ward, K. Lautenbach, and R. D. Murray. 1993b. Behaviour of lame and normal dairy cows in cubicles and in a straw yard. Vet. Rec. 133:204-208.

Sogstad, A. M., T. Fjeldaas, O. Osteras, and K. P. Forshell. 2005. Prevalence of claw lesions in Norwegian dairy cattle housed in tie stalls and free stalls. Prev. Vet. Med. 70:191-209.

Sogstad, A. M., O. Osteras, and T. Fjeldaas. 2006. Bovine claw and limb disorders related to reproductive performance and production diseases. J. Dairy Sci. 89:2519-2528.

Somers, J. G., K. Frankena, E. N. Noordhuizen-Stassen, and J. H. M. Metz. 2005. Risk factors for interdigital dermatitis and heel erosion in dairy cows kept in cubicle houses in The Netherlands. Prev. Vet. Med. 71:23-34

Tarlton, J. F., D. E. Holah, K. M. Evans, S. Jones, G. R. Pearson, and A. J. F. Webster. 2002. Biomechanical and histopathological changes in the support structures of bovine hooves around the time of first calving. Vet. J. 163:196-204.

Telezhenko, E., and C. Bergsten. 2005. Influence of floor type on the locomotion of dairy cows. Appl. Anim. Behav. Sci. 93:183-197.

Toussaint Raven, E. 1985. Cattle Footcare and Claw Trimming. Farming Press Ltd., Ipswich, UK.

Tranter, W. P. and R. S. Morris. 1992. Hoof growth and wear in pasture-fed dairy cattle. N. Z. Vet. J. 40:89-96.

Tucker, C. B., D. M. Weary, and D. Fraser. 2003. Effects of three types of free-stall surfaces on preferences and stall usage by dairy cows. J. Dairy Sci. 86:521-529

Van Amstel, S. R., J. K. Shearer, and F. L. Palin. 2004. Moisture content, thickness, and lesions of sole horn associated with thin soles in dairy cattle. J. Dairy Sci. 87:757-763.

Vermunt, J. J., and P. R. Greenough. 1995. Lesions associated with subclinical laminitis of the claws of dairy calves in two management systems. Br. Vet. J. 151:391-399.

Wells, S. J., L. P. Garber, and B. A. Wagner. 1999. Papillomatous digital dermatitis and associated risk factors in US dairy herds. Prev. Vet. Med. 38:11-24.

Whay, H. R. 2002. Locomotion scoring and lameness detection in dairy cattle. In Pract. 24:444-449.

Whay, H. R., A. E. Waterman, A. J. F. Webster, and J. K. O'Brien. 1998. The influence of lesion type on the duration of hyperalgesia associated with hindlimb lameness in dairy cattle. Vet. J. 156:2329 . 